\title{
Association of birthweight and penetrance of diabetes in individuals with HNF4A-MODY: a cohort study
}

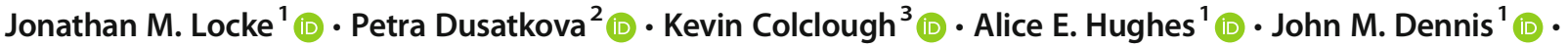 \\ Beverley Shields $^{1}$ (D) - Sarah E. Flanagan ${ }^{1}$ (D) $\cdot$ Maggie H. Shepherd ${ }^{1,4}$ (D) Emma L. Dempster ${ }^{1}$ (D) $\cdot$ \\ Andrew T. Hattersley ${ }^{1}$ (D) $\cdot$ Michael N. Weedon ${ }^{1}$ (D) $\cdot$ Stepanka Pruhova $^{2}$ (D) Kashyap A. Patel $^{1}$ (D)
}

Received: 1 June 2021 / Accepted: 16 August 2021 / Published online: 7 October 2021

(C) The Author(s) 2021

Keywords Birthweight $\cdot$ Hepatocytenuclear factor-4 alpha (HNF4A) $\cdot$ Maturity-onset diabetes of the young (MODY) $\cdot$ Penetrance

To the Editor: Mutations in HNF4A, which encodes hepatocyte nuclear factor- $4 \alpha$, cause maturity-onset diabetes of the young (MODY) [1]. HNF4A-MODY is also associated with congenital hyperinsulinism (CHI) and neonatal hypoglycaemia [2]. Our understanding of the transition from hyperinsulinism to diabetes is limited. One hypothesis is higher fetal insulin secretion triggers apoptosis and results in accelerated postnatal beta cell failure. Alternatively, HNF4A deficiency could cause distinct transcriptional defects in early and late life, leading to the contrasting insulin phenotypes $[2,3]$. These two hypotheses differ as to whether hypersecretion of insulin in utero precipitates beta cell failure later in life.

Fetal insulin secretion is known to be a major determinant of birthweight, particularly in humans $[4,5]$. Our analysis of individuals with complete absence of fetal insulin secretion, due to mutations in the insulin gene or pancreatic agenesis, have shown they are half the normal birthweight [5]. Additionally, in individuals with HNF4A mutations, macrosomia has been reported as always occurring in those with neonatal hyperinsulinaemic hypoglycaemia [2]. Thus, birthweight may be a useful bioassay of fetal insulin secretion.

Jonathan M. Locke

j.locke@exeter.ac.uk

$\triangle$ Kashyap A. Patel

k.a.patel@exeter.ac.uk

1 Institute of Biomedical \& Clinical Science, College of Medicine \& Health, University of Exeter, Exeter, UK

2 Department of Pediatrics, Second Faculty of Medicine, Charles University and University Hospital Motol, Prague, Czech Republic

3 Exeter Genomics Laboratory, Royal Devon and Exeter NHS Foundation Trust, Exeter, UK

4 Exeter NIHR Clinical Research Facility, Royal Devon and Exeter NHS Foundation Trust, Exeter, UK
In this study we sought to determine the association between birthweight and penetrance of diabetes in individuals with HNF4A mutations, which could provide insights into the relationship between fetal and adult insulin secretory capacity.

Data from genetic testing referral forms was extracted for all individuals with birthweight data and a rare (absent from gnomAD v2.1.1 [5]) pathogenic HNF4A mutation (Molecular Genetics laboratory, Exeter, UK $[n=204]$, and Motol University Hospital, Prague, Czech Republic $[n=59]$ ). Due to a lack of population-level sequencing data, which is needed to confidently define variant penetrance and pathogenicity, we then excluded a small number of individuals self-reported as nonWhite $(n=7)$. Individuals aged $<7$ years at study $(n=63)$ were also removed due to lack of diabetes presenting. Finally, for accurate determination of corrected birthweight, a small number of individuals self-reported as a twin $(n=4)$ or born $\leq 32$ weeks gestation $(n=3)$ were removed. This resulted in the cohort presented here $(n=186$, see electronic supplementary material [ESM] Table 1 for clinical characteristics). The characteristics of our cohort meant we calculated we had $>80 \%$ power to detect a $\mathrm{HR} \geq 1.43$ or $\leq 0.70$. BMI for children was adjusted to adult equivalent using the Child Growth Foundation reference standards [6]. Birthweights were corrected for gestation and sex using British 1990/UK-WHO growth standards [7] and calculated using the zanthro package [8]. Statistical analyses were performed using Stata v16 (StataCorp, Texas, USA). This study had ethical approval from the North Wales Research Ethics Committee (17/WA/0327) and Motol University Hospital Ethics Commitee.

We first sought to assess the impact of maternal diabetes and an HNF4A mutation on birthweight. The birthweight of individuals with a mutation was higher than that of family members without the mutation ( $4.17 \mathrm{~kg}$ [IQR $=3.60-4.71], n=186 \mathrm{vs}$ $3.66 \mathrm{~kg}[\mathrm{IQR}=3.30-4.18], n=31 ; p<0.001)$. The results were similar when analysis was restricted to individuals born to 


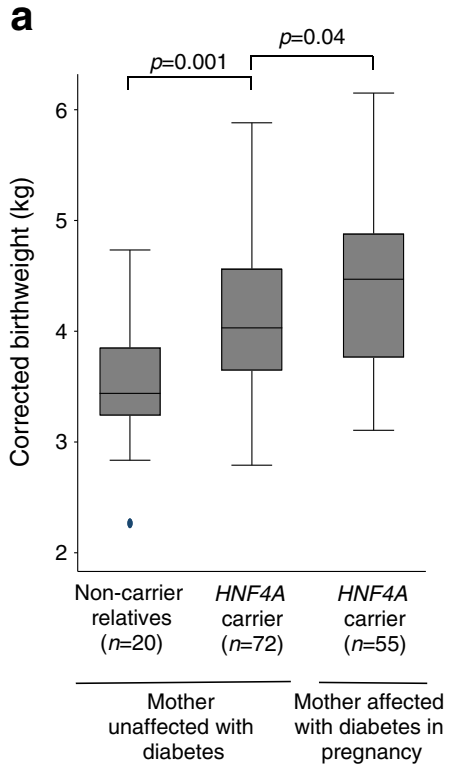

Fig. 1 HNF4A mutations are associated with a maternal glucose-independent increase in birthweight and a higher birthweight is associated with relative protection from diabetes. (a) Sex and gestation-corrected birthweights for individuals with $H N F 4 A$ mutations, split by presence of maternal diabetes during pregnancy, and non-carrier relatives. $p$ values were calculated by Mann-Whitney $U$ tests. The horizontal line within

mothers not reported to have diabetes $(4.03 \mathrm{~kg}[\mathrm{IQR}=3.64$ $4.56], n=72$ vs $3.44 \mathrm{~kg}[\mathrm{IQR}=3.24-3.85], n=20 ; p=0.001$ ) (Fig. 1a). Furthermore, for individuals with a mutation, those born to a mother with diabetes during pregnancy had an even higher birthweight than those born to a mother never reported to have diabetes $(4.47 \mathrm{~kg}$ [IQR $=3.76-4.88], n=55 \mathrm{vs} 4.03 \mathrm{~kg}$ [IQR $=3.64-4.56], n=72 ; p=0.04$ ) (Fig. 1a).

To assess the impact of birthweight on penetrance, we performed univariable Cox proportional-hazards survival analysis and found each per-kg increase was associated with a $22 \%$ reduction in diabetes diagnoses ( $\mathrm{HR}=0.78[95 \% \mathrm{CI}=0.62$, $0.97] ; p=0.03$ ) (Table 1). For those individuals with a birthweight less than $4.17 \mathrm{~kg}$ (cohort median), 50\% had developed diabetes by the age of 22 years, whereas for individuals with a birthweight more than $4.17 \mathrm{~kg}$, 50\% had developed diabetes by the age of 30 years (Fig. 1b). We observed similar results when analysis was limited to individuals with protein-truncating variants $(\mathrm{HR}=0.64,95 \% \mathrm{CI}=0.42,0.98, p=0.04)$, or a likely paternally inherited mutation (father reported to have diabetes each box represents the median, and the top and bottom of the box represent the 75 th and 25 th percentiles, respectively. The whiskers indicate the maximum and minimum values, excluding outliers. Filled circles indicate outliers. (b) Kaplan-Meier plot of survival from diabetes split by median birthweight for individuals with HNF4A mutations $(n=186)$

and/or mutation and mother reported not to have diabetes) (HR $=0.63,95 \% \mathrm{CI}=0.40,0.99, p=0.05$ ).

To assess if birthweight is independently associated with penetrance, we conducted multivariable Cox proportional-hazards survival analyses adjusting for other factors affecting penetrance. To identify factors associated with penetrance of $H N F 4 A-M O D Y$, we compared the characteristics of individuals with or without diabetes at 20 years of age (median age of diabetes diagnosis for cohort). Besides lower birthweight, being a proband, female, and born to a mother with diabetes during pregnancy was associated with earlier onset (all $p<0.05$ ) (ESM Table 2). After adjusting for these variables, the effect of birthweight on penetrance remained independent, with each per-kg increase associated with a $30 \%$ reduction in diabetes diagnoses $(\mathrm{HR}=0.70[95 \% \mathrm{CI}=0.54,0.91]$; $p=0.008$, Table 1).

We have found that, amongst individuals with highly penetrant HNF4A mutations, a higher birthweight is associated with
Table 1 Hazard ratios for factors associated with penetrance of HNF4A-MODY identified by Cox proportional-hazards survival regression analyses

\begin{tabular}{|c|c|c|c|c|}
\hline & \multicolumn{2}{|l|}{ Univariable } & \multicolumn{2}{|l|}{ Multivariable } \\
\hline & HR $(95 \% \mathrm{CI})$ & $p$ & HR $(95 \% \mathrm{CI})$ & $p$ \\
\hline Female & $1.40(1.00,1.98)$ & 0.053 & $1.60(1.09,2.34)$ & 0.015 \\
\hline Proband & $2.47(1.75,3.48)$ & $<0.001$ & $2.98(2.02,4.40)$ & $<0.001$ \\
\hline Mother with diabetes during pregnancy & $2.13(1.42,3.19)$ & $<0.001$ & $3.07(2.00,4.71)$ & $<0.001$ \\
\hline Corrected birthweight (per kg increase) & $0.78(0.62,0.97)$ & 0.03 & $0.70(0.54,0.91)$ & 0.008 \\
\hline
\end{tabular}


reduced penetrance of diabetes. We speculate that this reflects a correlation between an individual's fetal and adult insulin secretory capacity, such that there is a lesser reduction in adult beta cell function for individuals with an $H N F 4 A$ mutation and a higher birthweight. Direct measurement of perinatal glucose/insulin levels and longitudinal studies of beta cell function would enable firmer mechanistic conclusions, but these studies are inherently difficult and costly to perform.

We have recently reported that transfer to sulfonylureas is not universally successful for individuals with $H N F 4 A$-MODY, and that BMI and diabetes duration are predictors of transfer success [9]. Given the results presented here, we believe studies investigating treatment response with respect to birthweight and mother's diabetes status during pregnancy are warranted.

We previously reported a hypomorphic HNF4A missense mutation (p.R114W) associated with no increase in birthweight and reduced penetrance [10]. The requirement for mutations in this cohort to be absent from gnomAD should have limited the inclusion of individuals with similar, relatively common, hypomorphic mutations. If some hypomorphic mutations have been included, and act similarly to p.R114W, then their presence would result in an underestimation of the modifying effect of birthweight on penetrance. Future analyses of penetrance in population cohorts consisting of millions of sequenced individuals will be important for refining the effect size estimate.

In conclusion, this is one of the first and largest studies investigating the factors affecting penetrance of $H N F 4 A$ MODY, identifying birthweight as a modifier of potential prognostic and therapeutic relevance.

Supplementary Information The online version contains peer-reviewed but unedited supplementary material available at https://doi.org/10.1007/ s00125-021-05581-6.

Acknowledgements We would like to extend our gratitude to Petra Kucerova (Department of Pediatrics, Second Faculty of Medicine, Charles University and University Hospital Motol, Czech Republic) who assisted with data collection.

Data availability The datasets generated and/or analysed during the current study are available from the corresponding authors upon reasonable request.

Funding This research was funded in whole, or in part, by the Wellcome Trust (Grant numbers 219606/Z/19/Z and 105636/Z/14/Z). For the purpose of open access, the author has applied a CC BY public copyright licence to any Author Accepted Manuscript version arising from this submission. MHS is a National Institute for Health Research (NIHR) 70@70 Senior Nurse and Midwife Research Leader and is supported by the Exeter NIHR Clinical Research Facility at the University of Exeter. The NIHR Exeter Clinical Research Facility is a partnership between the University of Exeter Medical School College of Medicine and Health and Royal Devon and Exeter NHS Foundation Trust. The views expressed are those of the authors and not necessarily those of the NIHR or the Department of Health and Social Care. KAP is a Wellcome Trust Fellow (grant number 219606/Z/19/Z). SEF has a Sir Henry Dale Fellowship jointly funded by the Wellcome Trust and the Royal Society (grant number 105636/Z/14/Z). JMD is supported by an Independent Fellowship funded by Research England's Expanding Excellence in England (E3) fund. PD and SP are supported by the Ministry of Health of the Czech Republic (grant number NV18-0100078). AEH is supported by a Wellcome Trust Funded GW4 Clinical Academic Training Fellowship.

Authors' relationships and activities The authors declare that there are no relationships or activities that might bias, or be perceived to bias, their work.

Contribution statement JML, KAP, MNW, SEF, SP, and ATH made substantial contributions to conception and design. JML, KAP, PD, $\mathrm{KC}, \mathrm{AEH}, \mathrm{JMD}, \mathrm{BS}, \mathrm{MHS}, \mathrm{ELD}$, and SP were involved in acquisition of data or analysis and interpretation of data. JML, KAP, AEH, and MHS were involved in drafting the article or reviewing it critically for important intellectual content. All authors granted their final approval of the version to be published. JML and KAP are the guarantors of this work and, as such, had full access to all the data in the study and take responsibility for the integrity of the data and the accuracy of the data analysis.

Open Access This article is licensed under a Creative Commons Attribution 4.0 International License, which permits use, sharing, adaptation, distribution and reproduction in any medium or format, as long as you give appropriate credit to the original author(s) and the source, provide a link to the Creative Commons licence, and indicate if changes were made. The images or other third party material in this article are included in the article's Creative Commons licence, unless indicated otherwise in a credit line to the material. If material is not included in the article's Creative Commons licence and your intended use is not permitted by statutory regulation or exceeds the permitted use, you will need to obtain permission directly from the copyright holder. To view a copy of this licence, visit http://creativecommons.org/licenses/by/4.0/.

\section{References}

1. Yamagata K, Furuta H, Oda N et al (1996) Mutations in the hepatocyte nuclear factor-4alpha gene in maturity-onset diabetes of the young (MODY1). Nature 384(6608):458-460. https://doi.org/10. $1038 / 384458 \mathrm{a} 0$

2. Pearson ER, Boj SF, Steele AM et al (2007) Macrosomia and hyperinsulinaemic hypoglycaemia in patients with heterozygous mutations in the HNF4A gene. PLoS Med 4(4):e118. https://doi. org/10.1371/journal.pmed.0040118

3. Glaser B (2007) Type 2 diabetes: hypoinsulinism, hyperinsulinism, or both? PLoS Med 4(4):e148. https://doi.org/10.1371/journal. pmed.0040148

4. Fowden AL, Forhead AJ (2009) Endocrine regulation of fetoplacental growth. Horm Res 72(5):257-265. https://doi.org/10. $1159 / 000245927$

5. Hughes AE, Hattersley AT, Flanagan SE, Freathy RM (2021) Two decades since the fetal insulin hypothesis: what have we learned from genetics? Diabetologia 64(4):717-726. https://doi.org/10. 1007/s00125-021-05386-7

6. Freeman JV, Cole TJ, Chinn S, Jones PR, White EM, Preece MA (1995) Cross sectional stature and weight reference curves for the UK, 1990. Arch Dis Child 73(1):17-24. https://doi.org/10.1136/ adc.73.1.17 
7. Cole TJ, Williams AF, Wright CM, Group RGCE (2011) Revised birth centiles for weight, length and head circumference in the UKWHO growth charts. Ann Hum Biol 38(1):7-11. https://doi.org/10. 3109/03014460.2011.544139

8. Vidmar SI, Cole TJ (2013) Standardizing anthropometric measures in children and adolescents with functions for egen: update. Stata J 13(2):366-378. https://doi.org/10.1177/1536867X1301300211

9. Shepherd MH, Shields BM, Hudson M et al (2018) A UK nationwide prospective study of treatment change in MODY: genetic subtype and clinical characteristics predict optimal glycaemic control after discontinuing insulin and metformin. Diabetologia 61(12):2520-2527. https://doi.org/10.1007/s00125-018-4728-6

10. Laver TW, Colclough K, Shepherd M et al (2016) The common p.R114W HNF4A mutation causes a distinct clinical subtype of monogenic diabetes. Diabetes 65(10):3212-3217. https://doi.org/ $10.2337 / \mathrm{db} 16-0628$

Publisher's note Springer Nature remains neutral with regard to jurisdictional claims in published maps and institutional affiliations. 